\title{
Market incentives could bring U.S. agriculture and nutrition policies into accord
}

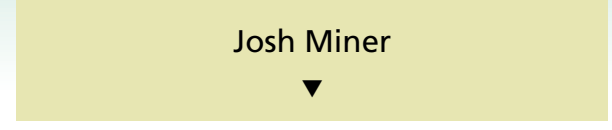

The U.S. Department of Agriculture (USDA) could help improve public health by creating a retail-based mechanism to provide participants in its Food Stamp Program (FSP) with significant monetary incentives to purchase health-promoting foods, such as minimally processed fruits, vegetables and whole-grain products. Increasing the consumption of such foods is of immediate importance in combating skyrocketing rates of diet-related chronic diseases such as heart disease, diabetes and obesity, all of which disproportionately affect low-income consumers. This incentive program could be paid for out of the tens of billions of dollars currently spent on annual commodity support payments. The redirected funds could be used to reimburse retailers and wholesaler-distributors for lost revenues, and to provide growers and processors with direct payments. The USDA would do well to consider such an approach because U.S. farm and nutrition policies often lack coherence and are not designed specifically to improve the health of U.S. consumers. This approach would also benefit California specialty crop growers, who currently receive a small proportion of federal subsidies and no direct commodity payments whatsoever.

Editor's note: The following article is a peer-reviewed perspective. Perspectives are review articles that interpret and analyze recent developments in research and public policy and express an opinion concerning the resulting impact on California's agricultural, natural and human resources.

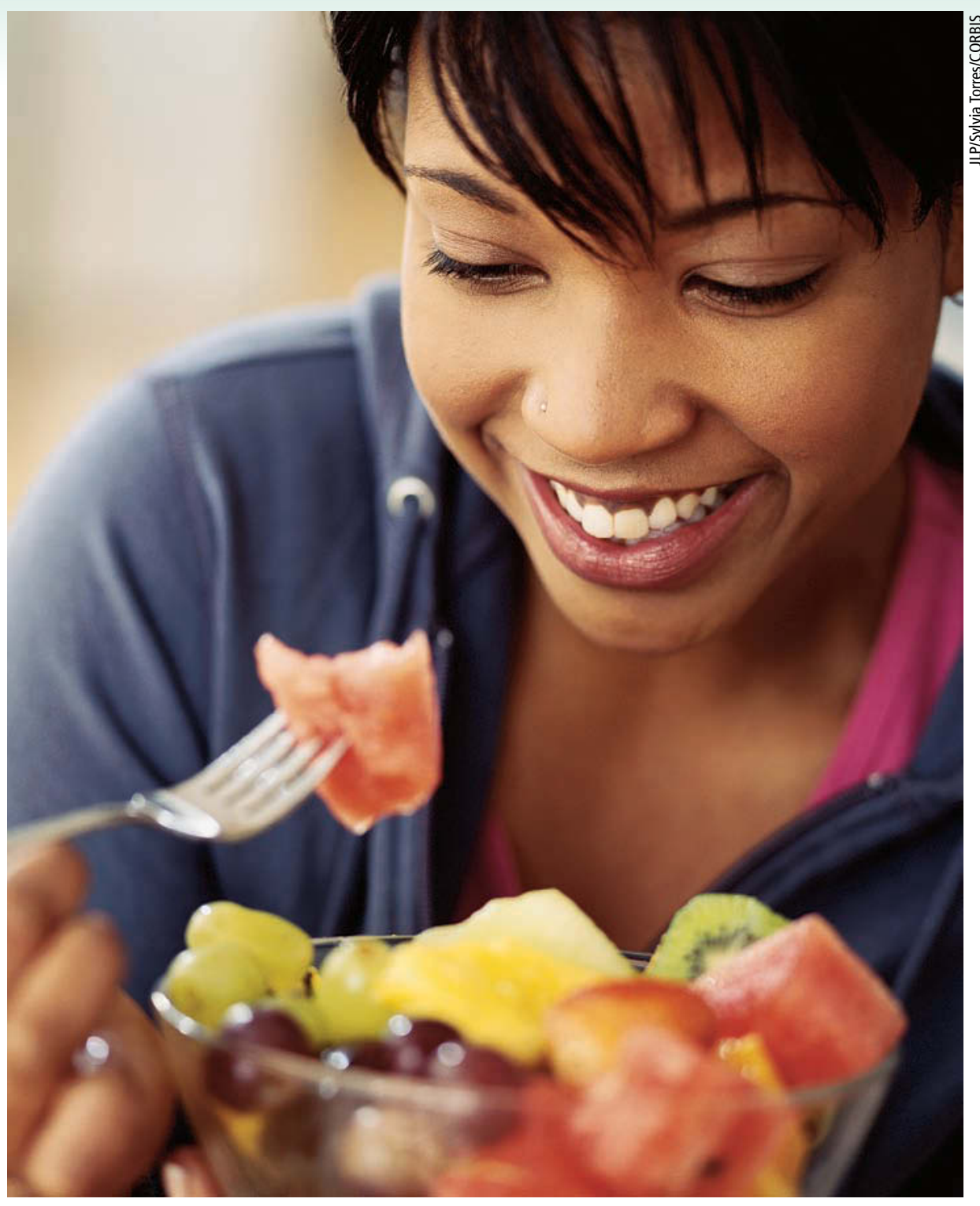

The author argues that current commodity-support programs do not promote public health goals, such as increasing the consumption of fruits and vegetables.

F very year, the U.S. government $\triangle$ authorizes the U.S. Department of Agriculture (USDA) to spend tens of billions of taxpayer dollars to support various agricultural and nutrition programs. Two in particular provoke both ire and unqualified support among elected representatives and other observers: the Food Stamp Program (FSP), which is operated by the Food and Nutrition Service (FNS), and the commodity support program, which is operated by the Farm Ser- vices Agency (FSA). This is partly due to the fact that the amounts spent are significant, but also because the potential impacts of these programs are questionable and extremely difficult to evaluate.

The Food Stamp Program is designed to augment the food budgets of qualified recipients, allowing them to purchase more food; the commodity support program ensures that commodity growers receive no less than a certain minimum price for their crops, 
TABLE 1. Food stamp benefit distributions, 2003

\begin{tabular}{lcc}
\hline & U.S. & Calif. \\
\hline Total benefits, in \$ millions & 21,400 & 127 \\
No. of recipient households & $9,200,000$ & $651,000 *$ \\
Average household & 195 & 195 \\
benefit (\$) & & \\
\hline * California's population comprised $12.2 \%$ of the U.S. \\
population in 2003 but received $7.3 \%$ of the nation's \\
food stamp benefits. \\
Source: USDA-FNS 2004.
\end{tabular}

even though market prices often fall significantly below that "price floor."

\section{Food stamps for low-income families}

U.S. citizens and some permanentresident aliens are qualified to participate in the FSP if they meet the following criteria: a gross monthly income below $130 \%$ of the federal poverty level, and a net monthly income below $100 \%$ of the federal poverty level $(\$ 1,698$ and $\$ 1,306$, respectively, for a family of three in fiscal year 2004-2005, in most places); less than $\$ 2,000$ in "countable resources," such as a bank account; the ability to meet work requirements for able-bodied adults; and the ability to provide a Social Security number for all household members. In 2003, the USDA distributed a total of $\$ 21.4$ billion in food stamp benefits to a monthly average of 9.2 million low-income households; each received an average of \$195 per month (table 1) (USDA FNS 2004).

Although the food stamp program has been shown to marginally increase the quantity of food consumed by participants, a review of the dietary impacts of U.S. food assistance programs found that "there is no convincing body of evidence that [the FSP] improves the overall quality of the recipients' diet, although there is some indication that it has increased the intake of some nutrients" (Levedahl and Oliveira 1999). (Each additional dollar of food stamp benefits increases recipients' food expenditures by 26 cents; the remaining 74 cents effectively were redirected toward other, nonfood items.)

While the correlation between income level and fruit and vegetable intake has not been examined, the proportion of consumers who eat at least five servings of fruits and vegetables daily is lower among black than white Americans;

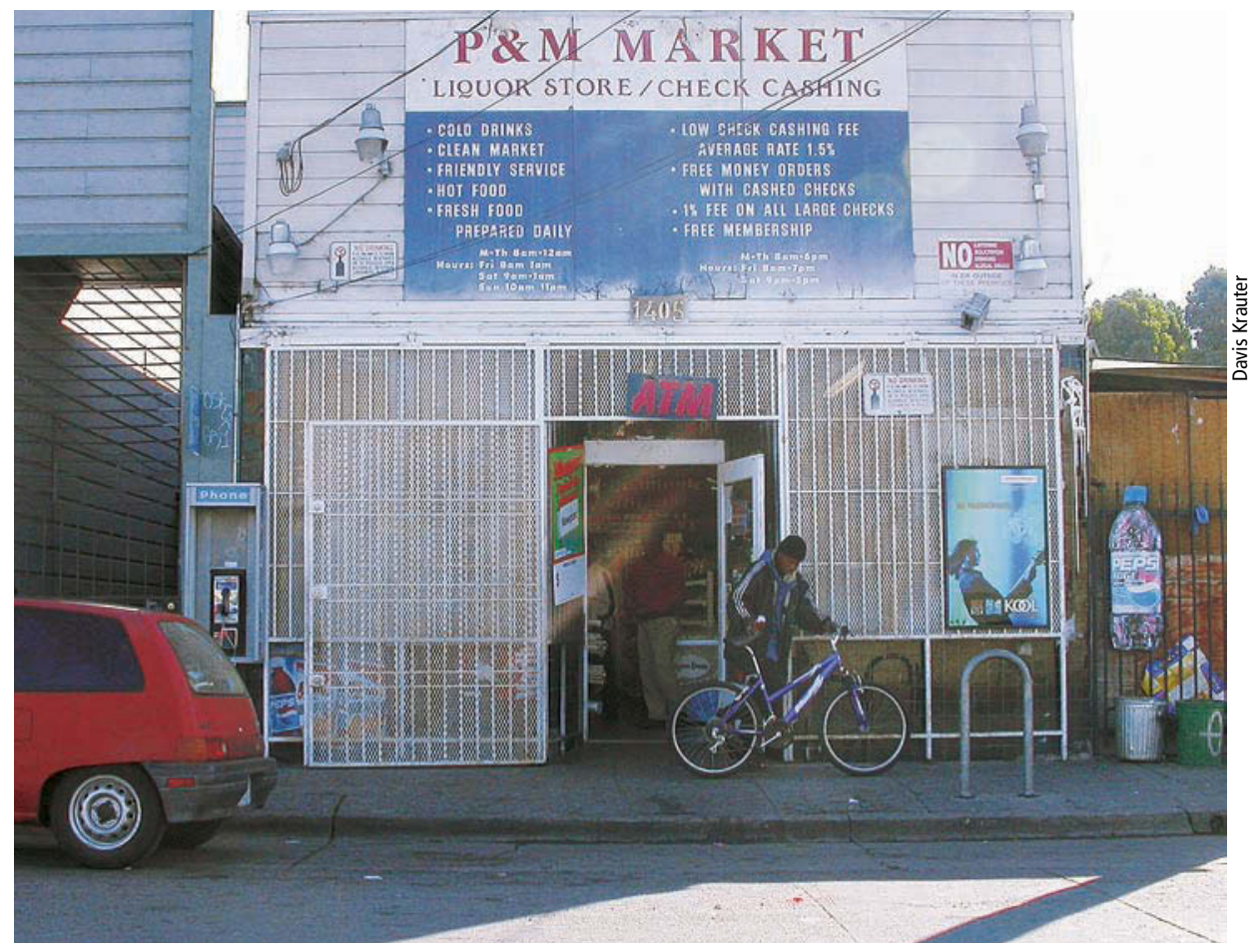

By implementing a system of market incentives, USDA could help to improve the "food environment" in low-income neighborhoods (such as, above, West Oakland), where residents often have easy access to liquor and fast food but have a harder time finding healthy, appealing, affordable food.

likewise, those with less than a high school education consume fewer servings than college graduates (Serdula et al. 2004). Essentially all Americans, and not just food stamp recipients, would benefit from purchasing and consuming more healthful food products. Increasing the purchasing power of low-income Americans, however, is of particular importance due to the fact that calories are most cheaply available in the form of added fats and sugars, while nutrientdense foods are often significantly more expensive by comparison (Drewnowski and Barratt-Fornell 2004).

Besides not improving participants dietary quality, the food stamp program also doesn't serve those eligible to receive benefits particularly well: in 2003 , only $61 \%$ of those eligible nationwide participated in the program, and in California only 39\% of those eligible participated (Food Research and Action Center 2003). Low participation rates represent, in the case of California alone, between $\$ 650$ million and $\$ 1.49$ billion in lost federal dollars annually (California Food Policy Advocates 2003).

There are several explanations for these participation rates. Potential foodstamp recipients often lack knowledge about eligibility criteria. In addition, the application process is notoriously difficult and dehumanizing, and the benefits are often perceived as not being worth the hassle. There is also persistent, and often well-founded, fear among immigrant communities that undocumented family members will be exposed to the U.S. Immigration and Naturalization Service (INS) by the application process for eligible individuals, such as U.S.born children. California's large immigrant community is an important factor contributing to the state's low food stamp participation rate.

\section{Commodity support for growers}

Direct commodity support payments are subsidies paid directly by the USDA-FSA to growers of crops such as corn, wheat, cotton, soybeans and rice to offset low prices in the marketplace. These price supports do not in all likelihood significantly affect the retail price of food products, because only a small portion of that price is attributable to the cost of subsidized ingredients. For example, the cost of high-fructose corn syrup in Coca-Cola or of corn in a box of Corn Chex represents only about $1 \%$ or less of the retail price.

However, subsidies depress commodity market prices by raising produc- 


\begin{tabular}{|c|c|c|c|c|c|c|}
\hline & & & \multicolumn{4}{|c|}{ Payment concentration } \\
\hline & \multicolumn{2}{|c|}{ Commodity payments } & \multicolumn{2}{|c|}{ Top $1 \%$ of recipients } & \multicolumn{2}{|c|}{ Top $20 \%$ of recipients } \\
\hline & U.S. & Calif. & U.S & Calif. & U.S. & Calif. \\
\hline Total payment, in \$ millions (\%) & ) 11,487 & 672 & $3,165(28)$ & $113(17)$ & $9,950(87)$ & $502(75)$ \\
\hline No. of farms (\%) & 1,556,819 (73) & $15,531(19.5)$ & 15,587 & 155 & 311,747 & 3,117 \\
\hline
\end{tabular}

tion levels above demand. By keeping commodity prices artificially low, price supports also encourage the use of commodities in processed foods and as animal feed. Because subsidy payments are directly linked to farm production levels and total farm revenues, the program also encourages overproduction (the more a farm produces, the larger the support payment for which it is eligible). The program is popular among large-scale commodity growers, who can receive millions of dollars each year, and legislators eager to show support for American farmers. It was therefore surprising to many that in early 2005 President Bush proposed placing a cap on commodity support payments of $\$ 250,000$ per grower. With the recent defeat of the Grassley-Dorgan amendment in the Senate, which would have established a $\$ 250,000$ cap on payments, whether that cap will be established will have to wait until the debate on the 2007 Farm Bill begins in earnest (see page 5).

Direct commodity payments are enormous and highly concentrated among the largest and most profitable growers. For example, $\$ 107.3$ billion was paid out between 1995 and 2003, with $87 \%$ of the $\$ 11.5$ billion spent in 2003 going to the top $20 \%$ of recipients (table 2) (Environmental Working Group 2004). Agricultural production in California is skewed heavily toward specialty crops such as fruits, vegetables and nuts, which do not qualify to receive direct payments. As a result, fewer California growers are eligible to receive commodity subsidies. In 2003, close to $20 \%$ did - mostly growers of rice, cotton and wheat; they received roughly $6 \%$, or $\$ 672$ million, of the U.S. total commodity payments in a similarly concentrated fashion (table 2) (Environmental Working Group 2004).

\section{Stronger links to public health}

The food stamp and commodity support programs illustrate that U.S. agricultural and nutrition policies are not specifically designed to promote health or good eating habits. A considerable proportion of commodity payments, for example, is directed to crops that are used primarily to produce calories in the form of added fats (such as corn oil) or sugars (such as highfructose corn syrup) or as feed for livestock. What's more, the bulk of these payments goes to very large growers of commodities that are overproduced to such an extent that subsidies are necessary to offset low market prices. Similarly, the food stamp program

\section{Incentives might go a long way toward eliminating two of the main barriers that consumers cite as keeping them from eating a better diet: cost and access.}

supplements the incomes of millions of low-income Americans so that they can afford to purchase an adequate amount of calories, but does very little to influence the nutritional quality of their diets.

Unhealthful diets and inadequate fruit and vegetable intakes are the norm among most Americans, and diet-related chronic diseases such as diabetes, heart disease and obesity disproportionately affect low-income Americans. Making healthful foods more widely available and less expensive to consumers would help bring agriculture and nutrition policies into accord with public health goals, and would be good public policy (Nestle 2000). USDA Economic Research Service researchers recently highlighted the potential "unintended consequences" of policies to combat obesity - such as listing the number of calories on menus at fast-food restaurants or levying taxes on snack foods - and concluded that such policies would in all likelihood not cause consumers to choose healthier foods (Kuchler et al. 2005). These researchers also examined the relative importance of economic and behavioral factors in influencing fruit and vegetable choices (Guthrie et al. 2005). Research has demonstrated that cost significantly influences consumer food choices, especially among low-income consumers, and that retail price reductions are an effective method to increase the purchase of more healthful foods (Glanz et al. 1998; French 2003).

\section{Incentives to improve nutrition}

There is no question that the food stamp and commodity support programs would distribute payments quite differently if the goals of both were explicitly to promote better eating habits among U.S. consumers. Increasing the level of benefits or expanding food stamp eligibility criteria is always a contentious and politically difficult issue. This is truer than ever now, with

pressing fiscal issues preventing the expansion of most federal programs. How, then, can we influence the dietary quality of food stamp recipients, especially given the fact that increased benefits are unlikely to cause recipients to purchase healthier foods?

I argue that the answer lies in creating marketplace incentives targeted to certain products (such as minimally processed fruits, vegetables and whole-grain foods), rather than the current FNS approach of developing nutrition-education and social-marketing messages (such as the 5 A Day campaign for promoting fruit and vegetable consumption). Congress and the USDA could create such an incentive program for food stamp participants by redirecting part or all of the funding currently distributed through the commodity support program. Any cuts or changes to the commodity support program would 


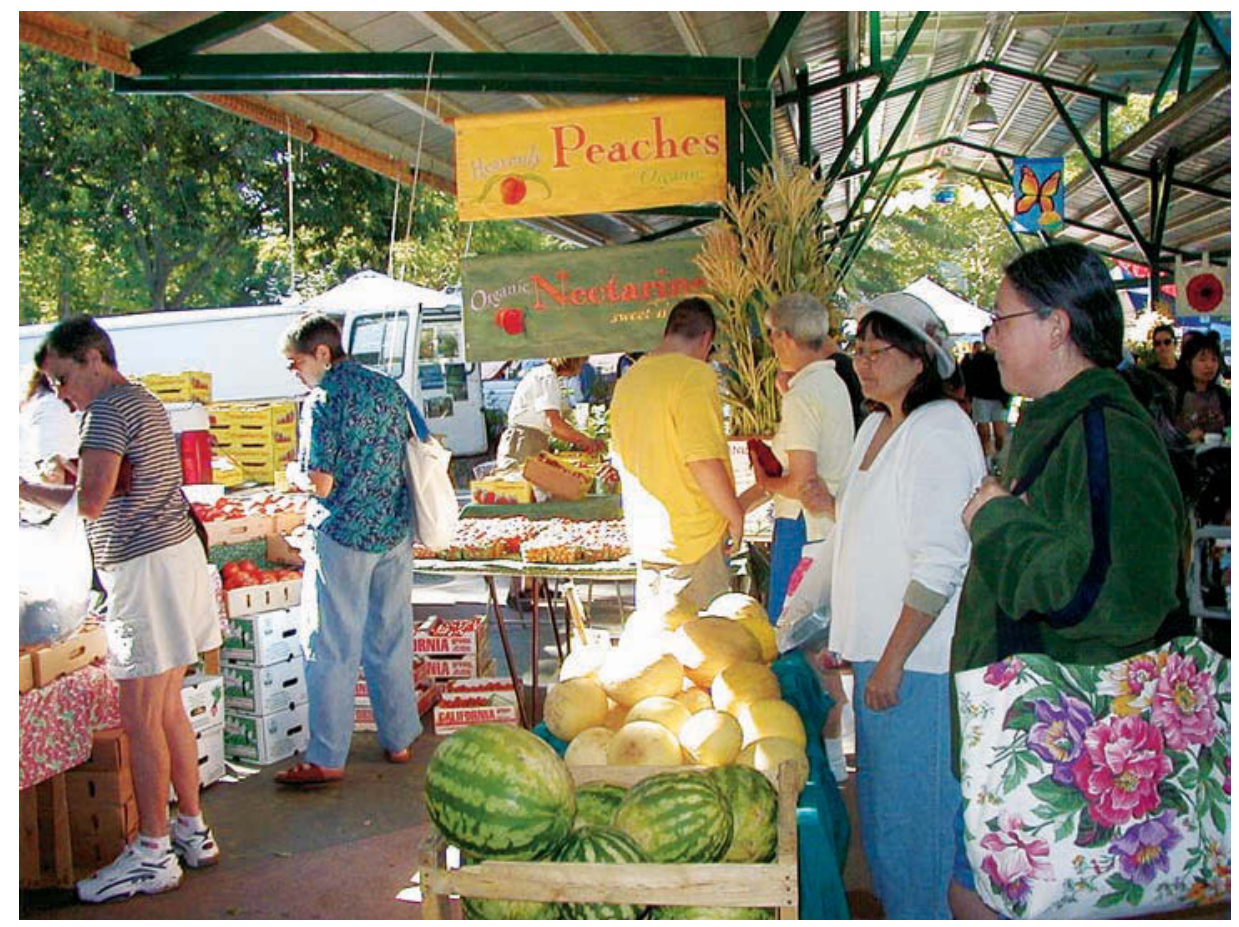

probably have to be designed to minimize impacts to existing food assistance programs, depending on commodity distribution. For example, some commodities that currently qualify for direct payments - which eventually make their way to entities such as food banks and schools through FNS food distribution programs - could be negatively affected by a reduction in commodity availability and price.

A FSP incentive program could reduce the retail price of healthful food items by providing retailers, wholesalerdistributors and growers with reimbursements and direct subsidies to cover costs and lost revenues. Lower costs would lead to increased demand, which, coupled with targeted subsidies and reimbursements, would act to stimulate production and increase retail access. The enactment of country-oforigin labeling laws would provide a mechanism to ensure that only products of U.S. growers would qualify.

Such an incentive program might work as follows. Food stamp recipients would receive a significant discount $-50 \%$, for example - when they use benefits to purchase qualified products that meet certain nutritional guidelines at FNS-authorized retail stores. FNS would then direct reimbursements to retailers, wholesalerdistributors and growers to make up for decreased revenues at the retail level. Because roughly $30 \%$ of the retail price of fruits and vegetables represents gross retail profits, reducing retail prices by $50 \%$ would allow for retail profit margins to remain constant with decreased revenues coming out of product costs, which would be paid by USDA directly to wholesaler-distributors. A similar transfer would occur at the wholesale level, with the USDA paying up to $100 \%$ of the amount normally paid to growers - roughly $20 \%$ of the retail price.

The USDA would ensure that everyone's gross profit remains constant. To do so, it would actually not need to reimburse the retailer for lost revenues at all (although retailers may need to be reimbursed for some administrative costs). The retailer would continue to purchase
To encourage produce consumption among low-income consumers, the USDA could expand its Farmers' Market Nutrition Program, which provides $\$ 20$ million in coupons annually to low-income and elderly persons for farmers' market purchases. Left, shoppers at the popular Davis Farmers Market.

produce from wholesaler-distributors, but a portion of that payment would in fact be made by the USDA, effectively discounting the price for retailers. This would allow retailers to charge customers a lower retail price while paying for costs and generating the same gross profits off larger gross margins, due to decreased product costs. Instead of dedicating $70 \%$ of the retail price to pay for product costs, the retailer would now dedicate only $40 \%$, thereby generating the same gross profits off a larger gross margin (60\% vs. $30 \%)$. The USDA would make payments at the farm gate and at the wholesale level. It would pay the wholesaler-distributor three-fifths of the discount, ensuring that the gross profit at the wholesale level remains equal to what it was before the price was discounted to the retailer. The remaining two-fifths would be paid to the grower, ensuring that their payments remain unchanged as well (table 3 ).

Needless to say, the exact manner in which the USDA would pay reimbursements would need to be carefully designed and implemented to avoid market distortions and fraudulent activities. Similarly, the method for determining which foods do and do not qualify for discounts would need to be developed by an entity not influenced by the food industry or particular crop associations - perhaps the Institute of Medicine, which was recently charged with reformulating the Women, Infants, and Children (WIC) food package.

\section{Small and local growers}

So far, I have discussed targeting incentives to purchases made only at traditional, FNS-authorized retail outlets such as supermarkets. Such a pro-

TABLE 3. Cost before and after proposed program for 1 pound of apples selling at $\$ 1$ per pound

\begin{tabular}{|c|c|c|}
\hline Apples & Before & After \\
\hline Retail & $\$ 1.00 / \mathrm{lb}(\$ 0.70$ cost $+\$ 0.30$ gross profit) & $\$ 0.50 / \mathrm{lb}(\$ 0.20$ cost $+\$ 0.30$ gross profit $)$ \\
\hline Wholesale-distributor & $\$ 0.70 / \mathrm{lb}(\$ 0.20$ cost $+\$ 0.50$ gross profit) & $\$ 0.20 / \mathrm{lb}+\$ 0.30 / \mathrm{lb}$ from USDA ( $\$ 0.00$ cost $+\$ 0.50$ gross profit) \\
\hline Grower & $\$ 0.20 / \mathrm{lb}$ (cost/profit breakdown unknown) & $\$ 0.00 / \mathrm{lb}+\$ 0.20 / \mathrm{lb}$ from USDA \\
\hline
\end{tabular}




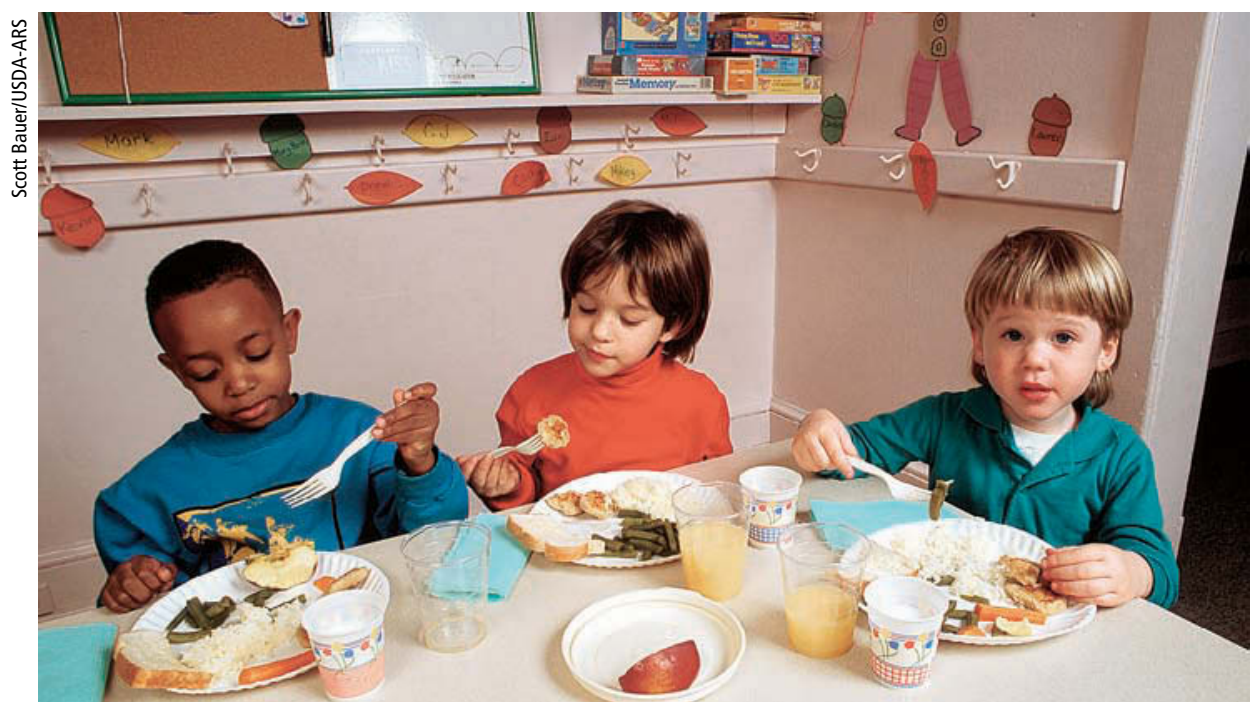

Changes to commodity support programs would need to be carefully designed to avoid negative impacts on USDA food distribution programs, such as those that serve food banks and schools. However, because such entities are in far greater need of low-cost, fresh produce than they are of USDA commodities, directing subsidies toward produce production and distribution could positively affect these programs as well.

gram would no doubt provide indirect incentives for the expansion of fruit and vegetable production nationwide (among other food products). But because the vast majority of produce supplied to the conventional retail grocery industry is grown on the largest, most profitable farms, the bulk of payments would still be directed to those farms, as is the case currently with the commodity support program. However, the USDA could use this opportunity to ensure that smaller-scale and regionally based growers engaged in direct marketing benefit as well, by expanding the Farmers' Market Nutrition Program, another FNS program that distributes coupons to WIC recipients and qualified seniors onceyearly on an annual federal budget of only around \$20 million (Joy et al. 2004). Food stamp recipients, and perhaps WIC recipients, might also receive a 50\% discount when benefits were used to purchase qualifying products at certified farmers' markets, with reimbursements going to growers and market operators instead of wholesaler-distributors.

Dedicating other funding, perhaps through the Risk Management Agency or Agriculture Marketing Service, toward a farmers' market incentive program could increase the amount of discount offered, and provide farmers' market operators and participating growers with a level of reimbursements necessary to subsidize the develop- ment and operation of farmers' markets in currently underserved low-income neighborhoods.

\section{How incentive program would work}

Costs. When crunching the numbers, one finds that a redirection of all 2003 farm commodity payments (nearly $\$ 11.5$ billion) to a marketplacebased incentive program would represent \$104 per month per food stamp household, or a $56 \%$ increase in the average monthly household benefit. Redirecting the $87 \%$ of farm commodity payments paid to the top $20 \%$ of farms (almost $\$ 10$ billion) would provide each food stamp household with an additional $\$ 90(46 \%)$ in purchasing power each month. Remember that these dollars are not being paid directly to food stamp participants as benefits, but rather to retailers, wholesalerdistributors and growers to create retail price reductions that apply to purchases made by participants. Furthermore, it is unlikely that these incentives would simply result in product substitution, because food stamp recipients - like the majority of Americans - do not currently purchase significant quantities of fruits, vegetables and whole-grain products.

Benefits. Many low-income Americans find healthful foods expensive and hard to find, and they need and deserve targeted assistance to help purchase them. A typical food stamp household, with one female adult and two children ages 3 and 7 , might receive roughly $\$ 250$ in benefits each month. (According to the USDA, 86\% of all food stamp households contain children, and the "average" food stamp household with children had 3.3 people [compared to 2.3 people for all households] and received \$268 per month in benefits.)

The Thrifty Food Plan (TFP) is an economic model developed by the USDA Center for Nutrition Policy and Promotion to create a "market basket" of items that meet U.S. Dietary Guidelines for nutrient intakes while constraining costs; the TFP is used as the basis for food stamp allotments and assumes that all food is purchased at stores and prepared at home. According to the USDA, the monthly cost of the TFP for this family in July 2003 - containing 25.2 pounds of vegetables other than potato products and 46.48 pounds of fruit - was $\$ 301.20$ (\$51.20 after deducting food stamp benefits), of which perhaps $\$ 100$ is allocated to purchase fruits and vegetables. However, it is highly unlikely that our typical food stamp family is following the TFP and purchasing anything close to 70 pounds of fruits and vegetables each month. This is because over half of all food purchases today are consumed outside the home, and because fruits and vegetables are often much more expensive and less available in the inexpensive restaurants, small neighborhood markets, and food-service settings likely to be frequented by lowincome Americans.

What would in effect be half-off sales would provide a significant incentive for food stamp recipients to purchase more nutritious foods. Although these "sales" certainly would not guarantee that all food stamp recipients meet the recommendations in the 2005 Dietary Guidelines for Americans overnight, such incentives would no doubt cause a great many recipients to start purchasing and eating more health-promoting 
By reconfiguring federal commodity-support programs, the author argues that USDA could invest in the good dietary habits of low-income Americans while creating new markets for the growers of healthy foods. Currently, the vast majority of commodity subsidies go to largescale growers of corn, soybeans, cotton, rice and, below, wheat.
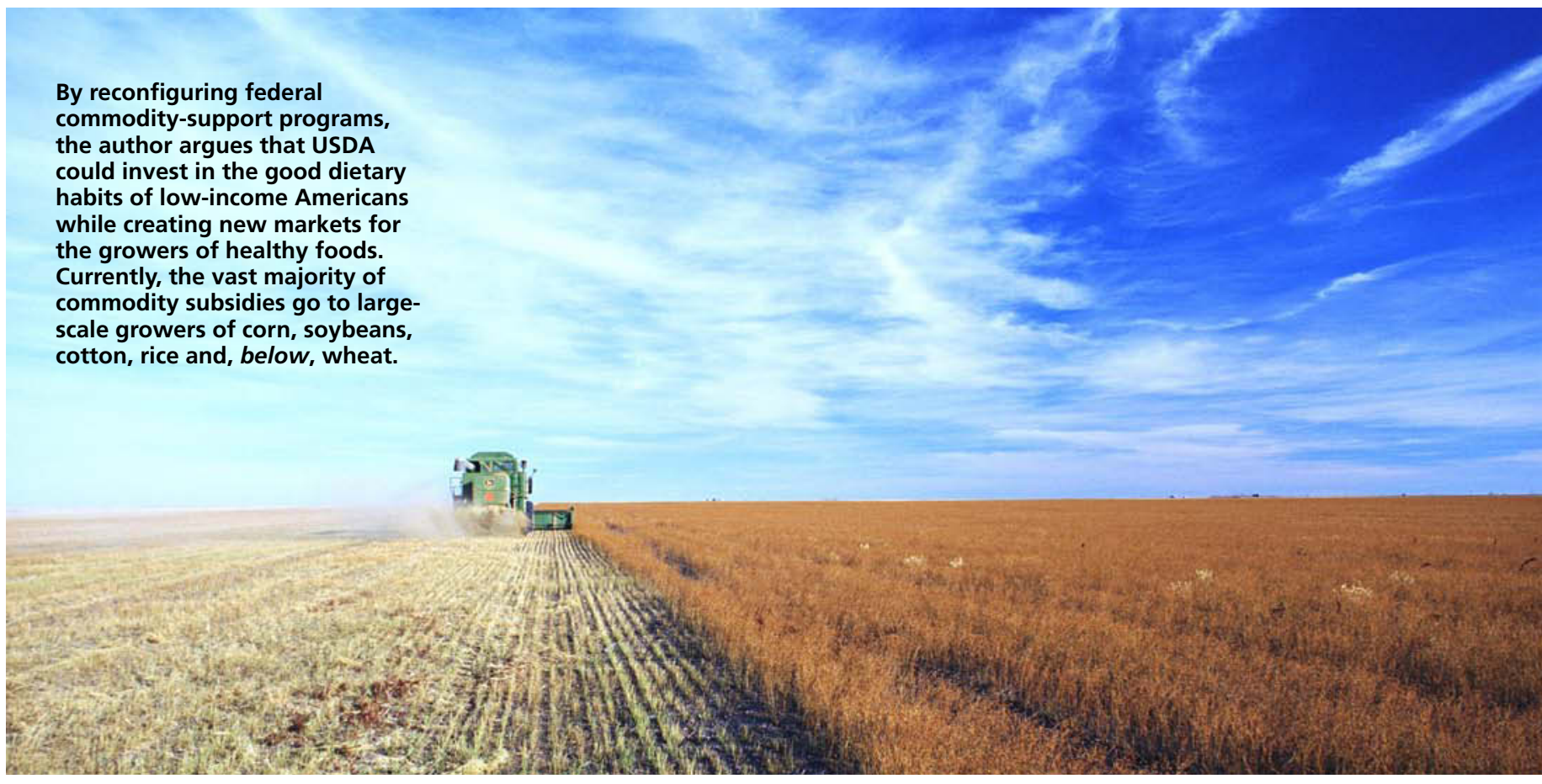

foods such as fruits, vegetables and whole grains (USDA-HHS 2005). In fact, these incentives might go a long way toward eliminating two of the main barriers that consumers cite as keeping them from eating a better diet: cost and access. What's more, by linking incentives directly to products that have known health benefits, there is a high likelihood that these redirected subsidies would result in additional future cost savings, in the form of improved health, increased productivity, and other economic and social benefits.

With such significant potential impacts, one must ask why the USDA isn't more willing to consider making targeted cuts in the commodity support program in order to improve (but not necessarily expand, in terms of eligibility criteria or benefit levels) the FSP. Does it really make sense to support the production of products such as high-fructose corn syrup by giving corn growers direct subsidy payments, and to support the purchase of products like Coca-Cola by giving food stamp recipients benefits but no incentives to spend extra for nutrients instead of maximizing calories? Why not instead invest in the health and good dietary habits of low-income Americans, while providing marketplace support for the producers of health-promoting food products? The USDA and members of Congress would do well to ask themselves these questions, perhaps while they're debating the 2007 Farm Bill (see page 5).

J. Miner is Food and Society Policy Fellow and Food Stamp Nutrition Education Program Food System Analyst, UC Cooperative Extension, Alameda County. The author would like to thank two anonymous reviewers for their comments. This paper was supported by a fellowship in the Food and Society Policy Program of the W.K. Kellogg Foundation.

\section{References}

California Food Policy Advocates. 2003. Lost dollars, empty plates. www.cfpa.net/ LostDollars2003.pdf (accessed July 22, 2005).

Drewnowski A, Barratt-Fornell A. 2004.

Do healthier diets cost more? Nutrition Today 39(4):161-8.

Environmental Working Group. 2004. Farm Subsidy Database, Commodity Programs, U.S. and California Summaries, 1995-2003. www.ewg.org/farm/region. php?fips=00000 (accessed June 22, 2005).

Food Research and Action Center. 2003. Food Stamp Participation Access Rates Stateby-State. www.frac.org/html/federal_food_ programs/FSP/Participation_Rates_03.html (accessed July 22, 2005).

French SA. 2003. Pricing effects on food choices. J Nutrition 133:841S-3S.

Glanz K, Basil M, Maibach E, et al. 1998. Why Americans eat what they do: Taste, nutrition, cost, convenience, and weight contro concerns as influences on food consumption J Amer Dietetic Assoc 98:1118-26.
Guthrie JF, Lin B-H, Reed J, Stewart H. 2005. Understanding economic and behavioral influences on fruit and vegetable choices. Amber Waves, April. www.ers.usda. gov/Amberwaves/April05/Features/FruitAndVegChoices.htm (accessed June 22, 2005).

Joy AB, Bunch S, Davis M, Fujii J. 2001. USDA program stimulates interest in farmers' markets among low-income women. $\mathrm{Cal} \mathrm{Ag}$ 55(3):38-41

Kuchler F, Golan E, Variyam JN, Crutchfield SR. 2005. Obesity policy and the law of unintended consequences. Amber Waves, June. www.ers.usda.gov/AmberWaves/ June05/Features/ObesityPolicy.htm (accessed June 22, 2005)

Levedahl JW, Oliveira V. 1999. Dietary impacts of food assistance programs. In: Frazao E (ed.). America's Eating Habits. US Department of Agriculture, Economic Research Service, Washington, DC. p 322.

Nestle M. 2000. The ironic politics of obesity. Science 299(5608):781.

Serdula MK, Gillespie C, Kettel-Khan L, et al. 2004. Trends in fruit and vegetable consumption among adults in the United States: Behavioral Risk Factor Surveillance System, 1994-2000. Amer J Public Health 94(6):1014-8.

[USDA-FNS] US Department of Agriculture, Food and Nutrition Service. 2004. Office of Analysis, Nutrition and Evaluation. Characteristics of Food Stamp Households, Fiscal Year 2003. www.fns.usda.gov/oane/ MENU/Published/FSP/FILES/Participation/ 2003Characteristics.pdf (accessed June 22, 2005).

[USDA-HHS] USDA Department of Health and Human Services. 2005. Dietary Guidelines for Americans. www.healthierus.gov/dietaryguidelines.

[USDA-NASS] USDA National Agricultural Statistics Service. 2004. 2002 Census of Agriculture. www.nass.usda.gov/census (accessed June 22, 2005). 